\title{
ACEMIS: SOFTWARE FOR THE COMPUTATION OF AIRCRAFT FLIGHT EMISSIONS BASED ON FUEL CONSUMPTION
}

\author{
SUDEEP ARYAL SHARMA, HAROLD BARBEY, REMI JULIO, KEVIN COCQ, \\ JEREMY CURE, ARNAUD GLARIA \& VALERIE LAVASTE \\ TEC (Technology and Engineering Center), Capgemini Engineering, France
}

\begin{abstract}
The world has witnessed a significant growth in air traffic over the past 50 years. While this may be a good thing for a country's economy, increase in pollution and rise in temperature, due to the growth of greenhouse gas (GHG) emissions are worrying factors. Thus the methods to track pollutants emitted by flights, in order to mitigate the pollution, have become of utmost importance. ACEMIS (AirCraft EMISsion), presented in this paper, is a tool developed for the calculation of emissions based on fuel consumption of flights. The input data is one of the most important factors to create a realistic simulation and this paper explains how several influencing factors and actual flight data are considered for computation. It also explains the computational methodology to calculate the fuel consumption of a flight and simulate realistic emissions of not only carbon dioxide $\mathrm{CO}_{2}$ but other gaseous emissions such as nitric oxides/nitrogen dioxide $\mathrm{NO}_{x}$, water $\mathrm{H}_{2} \mathrm{O}$, carbon monoxide $\mathrm{CO}$, hydrocarbons $\mathrm{HC}$, and sulfur dioxide $\mathrm{SO}_{2}$. This novel tool enables the user to simulate chemical emissions of a flight or a fleet between two or more airports, then displays and analyzes the simulation results. Finally, this calculation method is encoded using Python programming language to create a graphical friendly user interface.
\end{abstract}

Keywords: environment, aircraft, aeronautics, Python, greenhouse gas emission, GHG, pollution, carbon dioxide.

\section{INTRODUCTION}

The economic growth in the aeronautical sector, illustrated by novel airports creation (among others), has resulted in 8\% increase in air traffic between 2014 and 2017, with a forecast of $42 \%$ increase from 2017 to 2040 [1]. The amplification of air traffic proportionally increases emissions of pollutants as fuel burn process in flight generates byproducts such as greenhouse gases (GHG). The significant emissions are carbon dioxide $\mathrm{CO}_{2}\left(70 \%\right.$ of the exhaust), water vapor $\mathrm{H}_{2} \mathrm{O}$ (30\%), sulfur dioxide $\mathrm{SO}_{2}$, nitric oxide/nitrogen dioxide $\mathrm{NO}_{x}$, carbon monoxide $\mathrm{CO}$ and hydrocarbons $\mathrm{HC}$ (around $1 \%$ of the exhaust combined). There are many studies focusing on the impact of $\mathrm{CO}_{2}$ onto the environment, whereas other flight emissions have been historically ignored. This has to change in order to act significantly against the negative impact of the aeronautic sector on the environment. The United Nations' Intergovernmental Panel on Climate Change (IPCC) published one of the first reports on the impact of non- $\mathrm{CO}_{2}$ emissions in 1999 highlighting the contribution of $\mathrm{NO}_{\mathrm{x}}$ at high altitudes in the depletion of ozone layer [2]. Water vapor forms cirrus-clouds at high altitude, which has a serious warming effect despite its short life span because of the collective effect of thousands of continuous flights [3]. The climate impacts of $\mathrm{NO}_{\mathrm{x}}$, contrails, and clouds due to $\mathrm{H}_{2} \mathrm{O}$ emitted at high altitude is so strong that they can eat the planet more in one day than all the aviation's $\mathrm{CO}_{2}$ accumulated in the atmosphere since the 1940s [4]. Hence, it has become increasingly important today and in the future to keep a record on $\mathrm{GHG}$ and/or pollutant emissions like $\mathrm{H}_{2} \mathrm{O}, \mathrm{SO}_{2}, \mathrm{NO}_{\mathrm{x}}, \mathrm{CO}$ and $\mathrm{HC}$, in addition to $\mathrm{CO}_{2}$. 
$\mathrm{CO}_{2}$ emissions from aviation have been included in the EU emissions trading system (EU ETS) since 2012. Under the EU ETS, all European and non-European airlines operating in Europe are required to monitor, report, and verify their emissions, then they may have to pay allowances against those emissions. Every year, they receive tradeable allowances covering a certain level of emissions from their flights [5]. In 2016, the International Civil Aviation Organization (ICAO) agreed on a resolution for a global market-based measure to address $\mathrm{CO}_{2}$ emissions from international aviation as of 2021 [6]. The agreed resolution sets out the objective and key design elements of the global scheme, as well as a roadmap for the completion of the work on implementing modalities. The Carbon Offsetting and Reduction Scheme for International Aviation (CORSIA) program aims to stabilize $\mathrm{CO}_{2}$ emissions at 2019 levels by requiring airlines to offset the growth of their emissions after this date [6]. It however takes into account only $\mathrm{CO}_{2}$ emission.

To respect the regulation as set out by ETS or CORSIA, airlines must keep tracking all types of emissions contributing to global warming. Even though methods are proposed to gather the in-flight emissions data [7], there is currently no complete tool for the calculation of flight emissions other than $\mathrm{CO}_{2}$ [8]. To fill this gap and anticipate the future of aviation, the Capgemini Engineering group envisioned an emission and fuel consumption-tracking graphics friendly user interface (GUI) tool called ACEMIS (AirCraft EMISsions). It uses scientific calculation methodologies to simulate the fuel consumption and flight emissions $\left(\mathrm{CO}_{2}, \mathrm{NO}_{\mathrm{x}}, \mathrm{H}_{2} \mathrm{O}, \mathrm{CO}, \mathrm{HC}, \mathrm{SO}_{2}\right)$ in two ways, one by using MOZAIC or IAGOS data [9] from flights that have already taken place ("MOZAIC/IAGOS Fleet" part in the tool), and the other by building personalized flight routes ("Flight Profile" part in the tool, Fig. 1).

MOZAIC (Measurements of OZone, water vapor, carbon monoxide and nitrogen oxides by in-service AIrbus airCraft) is an observation program that took place between Aug. 1994 and Nov. 2014 [9]. Its purpose was to measure the composition of the atmosphere through commercial aircraft of various airlines. Several chemical components have been recorded: ozone $\left(\mathrm{O}_{3}\right)$, carbon monoxide $(\mathrm{CO})$, water vapor $\left(\mathrm{H}_{2} \mathrm{O}\right)$ and total nitrogen oxides $\left(\mathrm{NO}_{\mathrm{y}}\right)$. IAGOS (In-service Aircraft for a Global Observing System), which started in Jul. 2011 until today, is the continuation of the MOZAIC program and includes among others measurements of ozone $\left(\mathrm{O}_{3}\right)$, carbon monoxide $(\mathrm{CO})$, water vapor $\left(\mathrm{H}_{2} \mathrm{O}\right)$, nitrogen oxides $\left(\mathrm{NO}_{\mathrm{x}}, \mathrm{NO}_{\mathrm{y}}\right)$ and greenhouse gases $\left(\mathrm{CO}_{2}, \mathrm{CH}_{4}\right)$ [9]. All measurements are geo-localized (latitude, longitude, altitude...) and supplemented by meteorological data (temperature, pressure, humidity...).

\section{METHODOLOGY}

ACEMIS is a GUI software that calculates the fuel consumption and pollutant emissions. The user can enter flight information such as flight name, aircraft type, fuels used (and their concentration), weather conditions, departure and arrival airports, and passenger fill rate of the aircraft (Fig. 1). Realistic simulation can be done in the MOZAIC/IAGOS module using real flight data received from MOZAIC or IAGOS database [9], whereas personalized flight routes are simulated in the FLIGHT PROFILE module. The right part (red dashed line, Fig. 1) displays useful information such as fleet, progress of the simulation (inside the red dotted box) and the information of the selected flight.

In this section, the methodologies behind the fuel consumption and emissions calculation are explained. 


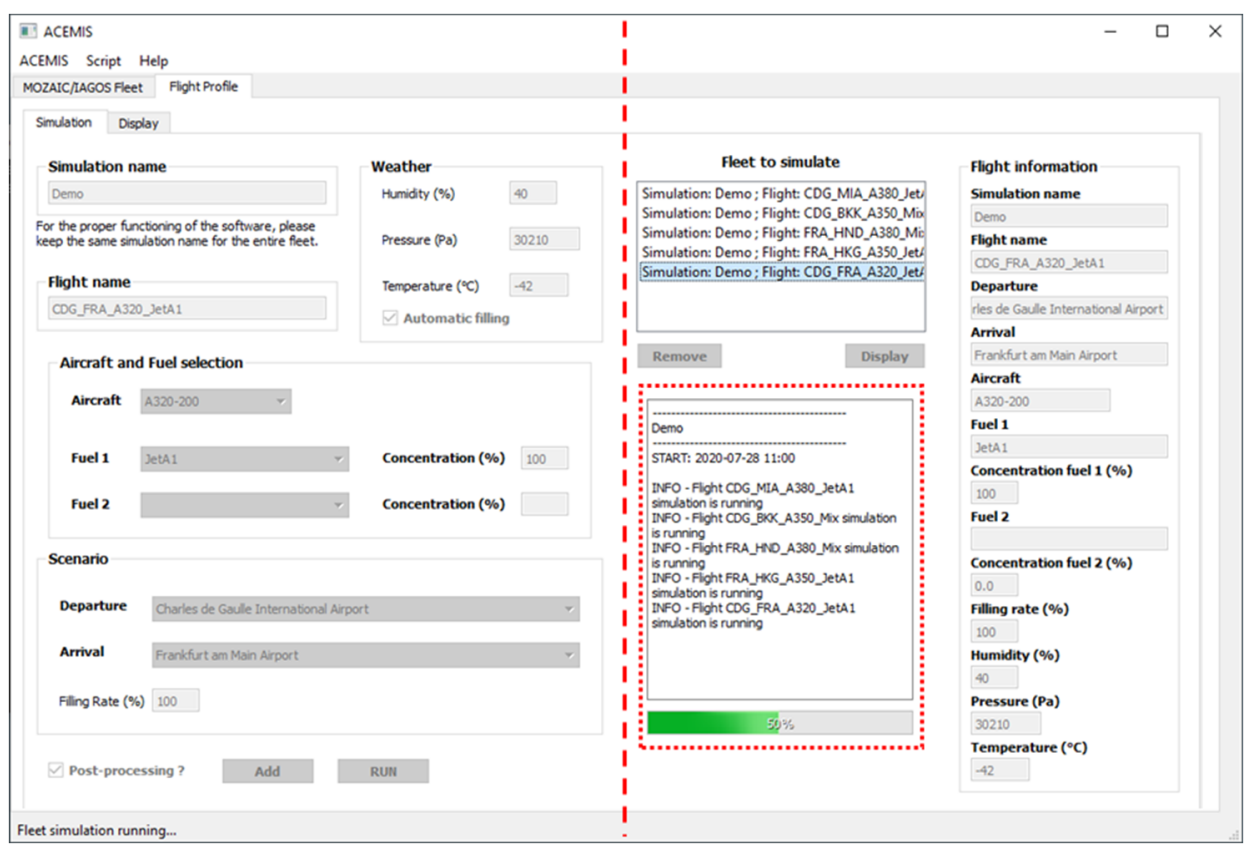

Figure 1: Graphical user interface of ACEMIS - version 2.1 - Flight Profile part.

\subsection{Calculation of fuel consumption}

The fuel consumption calculation requires data from the Auxiliary Power Unit (APU) and the engine: the standard thrust on the ground $\mathrm{Tr}_{00}$, the specific consumption $\mathrm{SFC}_{00}$, the fuel flow at idle speed $\mathrm{FF}_{\mathrm{IDLE}}$, and the fuel flow of the APU $\mathrm{FF}_{\mathrm{APU}}$. These data, together combined with the "aircraft" parameters and ambient conditions, make possible to calculate the rate of fuel burned by the aircraft at any point.

The fuel flow is the product of the specific fuel consumption and the thrust. Thrust is calculated differently depending on whether the aircraft is stabilized in the cruise phase, the climb phase, or the braking phase (this is referred as back thrust, eqns (1)-(3)). In the first case, the thrust is determined from the balance of forces acting on the aircraft; in the second case, an empirical method is used.

$$
\begin{aligned}
& \left\{\begin{array}{c}
\operatorname{SFC}(z, M)=S F C_{00} \times \sqrt{T(z) / T_{00}} \times(1+M) . \\
\operatorname{Tr}(z, M)=\operatorname{Tr}_{00} \times\left(0.568+\left[0.25 \times(1.2-M)^{3}\right]\right) \times\left[P(z) / P_{00}\right]^{0,6} \\
F F(z, M)=\operatorname{SFC}(z, M) \times \operatorname{Tr}(z, M) .
\end{array}\right. \\
& \left\{\begin{array}{c}
\operatorname{SFC}(z, M)=S F C_{00} \times \sqrt{T(z) / T_{00}} \times(1+M) . \\
\operatorname{Tr}\left(m_{A / C}\right)=\left(m_{A / C} \times g_{0}\right) \times[\cos \beta / f-\sin \beta] / n b_{e n g} . \\
F F(z, M)=\operatorname{SFC}(z, M) \times \operatorname{Tr}(z, M) .
\end{array}\right.
\end{aligned}
$$




$$
\left\{\begin{array}{c}
S F C(z, M)=S F C_{00} \times \sqrt{T(z) / T_{00}} \times(1+M) . \\
\operatorname{Tr}\left(m_{A / C}\right)=m_{A / C} \times\left(V_{I N V} / t_{T-D}\right) / n b_{e n g} . \\
F F(z, M)=S F C(z, M) \times \operatorname{Tr}(z, M) .
\end{array}\right.
$$

where:

- $\quad$ Atmospheric parameters: $T$ (temperature; K), $P$ (pressure; Pa), $R H$ (relative humidity);

- Aircraft parameters: $F F$ (fuel flow; kg. $\mathrm{s}^{-1}$ ), $\operatorname{Tr}$ (thrust; N), SFC (specific consumption), $M$ (Mach number), $m$ (mass; $\mathrm{kg}$ ), $n b_{\text {eng }}$ (number of engines), $V_{I N V}$ (reverse speed; $\left.\mathrm{m} . \mathrm{s}^{-1}\right), \mathrm{t}_{\mathrm{T}-\mathrm{D}}$ (duration of braking phase; $\left.\mathrm{s}\right)$;

- Indices: 00 (ground condition), eng (engine), $A P U$ (Auxiliary Power Unit), IDLE (idle phase), $A / C$ (aircraft);

- Other: $g_{0}$ (acceleration due to gravity $\left.=9.80665 \mathrm{~m} \cdot \mathrm{s}^{-2}\right), \gamma$ (isentropic coefficient of air $=$ 1.4), $r$ (specific ideal gas constant $=287.058 \mathrm{~J} \cdot \mathrm{K}^{-1} \cdot \mathrm{kg}^{-1}$ ), $f$ (finesse $=$ ration of coefficient of lift and drag; four possible configurations, noted from $f_{0}$ to $f_{3}$ ), $\beta$ (descent slope of the aircraft).

When using the $A P U$ during the parking phase, the fuel flow denoted $F F_{\text {eng }}$ and expressed in $\mathrm{kg} / \mathrm{s}$, can be summed up as follows in eqn (4):

$$
F F_{\text {eng }}=F F_{A P U} \text {. }
$$

Similarly, at idle speed, the fuel flow is provided by the ICAO data (eqn (5)):

$$
F F_{\text {eng }}=F F_{I D L E} \text {. }
$$

\subsection{Calculation of emissions}

Calculation of emissions requires the fuel flow value. The product of the fuel flow and the emission indices (ratio of mass of pollutant emitted and mass of fuel consumed) allows the calculation of the emission of the pollutant considered per unit of time during a flight. These calculations are done based on two methods: first, the complete combustion assumption for $\mathrm{CO}_{2}, \mathrm{H}_{2} \mathrm{O}$ and $\mathrm{SO}_{2}$ emissions, and second the Boeing Fuel Flow Method (BFFM2 method) for $\mathrm{NO}_{\mathrm{x}}, \mathrm{CO}$ and $\mathrm{HC}[10]$.

$$
\left\{\begin{array}{c}
E I\left(\mathrm{CO}_{2}\right)=m_{C} \times\left(M_{C}+2 . M_{O}\right) /\left(M_{C}\right) . \\
E I\left(\mathrm{H}_{2} \mathrm{O}\right)=m_{H} \times\left(M_{O}+2 . M_{H}\right) /\left(2 . M_{H}\right) . \\
E I\left(\mathrm{SO}_{2}\right)=m_{S} \times\left(M_{S}+2 . M_{O}\right) /\left(M_{S}\right) .
\end{array}\right.
$$

where:

- fuel parameters: $m$ (mass percentage of a compound; $\mathrm{kg} / \mathrm{kg}$ ), $M$ (molar mass of a compound; g.mol $\left.{ }^{-1}\right)$;

- Indices: C (carbon), $\mathrm{H}$ (hydrogen), O (oxygen), $\mathrm{S}$ (sulfur).

The BFFM2 method consists in extrapolating the emission indices at an altitude from the emission value on the ground affected by the ambient conditions - temperature, pressure and humidity [10]. This is done in three steps:

1. The calculation of fuel flow rate on the ground determined from the previously calculated consumption $\left(F F_{\text {eng }}\right)$, the ambient conditions $(T, P)$ and the speed of the aircraft $(M)$, eqn (7): 


$$
F F_{00}=F F_{\text {eng }} \times \frac{\left(T / T_{00}\right)^{3,8}}{\left(P / P_{00}\right)} \times e^{0,2 \times M^{2}} .
$$

2. Linear interpolation of ICAO data using above value to associate it with emission indices $\mathrm{EI}_{\mathrm{NOx}, 00}, \mathrm{EI}_{\mathrm{CO}, 00}$, and $\mathrm{EI}_{\mathrm{HC}, 00}$

3. Calculation of the aircraft's emission indices (eqn (8)) using the values obtained from step 2 above (in the absence of relative humidity data, the value of $50 \%$ is applied).

$$
\left\{\begin{array}{c}
E I_{N O x}(z)=E I_{N O x, 00} \times\left(\left(T / T_{00}\right)^{3.3} /\left(P / P_{00}\right)^{1.02}\right)^{-0.5} \times e^{-19(q-0.00634)} . \\
E I_{C O}(z)=E I_{C O, 00} \times \sqrt{\left(\left(T / T_{00}\right)^{3.3} /\left(P / P_{00}\right)^{1.02}\right)} . \\
E I_{H C}(z)=E I_{H C, 00} \times \sqrt{\left(\left(T / T_{00}\right)^{3.3} /\left(P / P_{00}\right)^{1.02}\right)} .
\end{array}\right.
$$

where:

- $\quad$ Aircraft parameters: $E I$ (emission indice of a pollutant; $\mathrm{kg} / \mathrm{kg}$ ), $F F$ (fuel flow rate; $\mathrm{kg} . \mathrm{s}^{-}$ $\left.{ }^{1}\right), M$ (Mach number at an altitude z);

- $\quad$ Atmospheric parameters: $T$ (temperature; K), $P$ (pressure; Pa), $q$ (specific humidity);

- Indices: 00 (ground parameter), eng (in-flight parameter).

\section{SIMULATION RESULTS}

In ACEMIS, the results could be analyzed under the "Display" tab. Within the sub-tab of "Flight" the result of one single flight can be displayed (Fig. 2). For the purpose of demonstration, the results of the flight trajectory, fuel flow rate, and emissions graph of $\mathrm{CO}_{2}, \mathrm{CO}$, and $\mathrm{NO}_{\mathrm{x}}$ in Fig. 2 are displayed for a flight from Paris Charles de Gaulle International Airport to Miami International Airport with an A380-800 aircraft, $100 \%$ JetA1 fuel and 99\% passenger fill rate. The weather conditions are the same as the cruise conditions.

From Fig. 2(b), the maximum fuel burn (ca. $7 \mathrm{~kg} \cdot \mathrm{s}^{-1}$ ) is reached during take-off and landing phases, which in turn produces more emissions (concentrated on a brief period of time, compared to the total time flight). At cruise, the fuel consumption is ca. $2 \mathrm{~kg} . \mathrm{s}^{-1}$. From Fig. 2(c), the $\mathrm{CO}_{2}$ emissions are ca. $22 \mathrm{~kg} . \mathrm{s}^{-1}$ during the take-off and landing phases, while it stabilizes at ca. $7 \mathrm{~kg} . \mathrm{s}^{-1}$ at cruise, correlated with the fuel consumption profile (Fig. 2(b)). Both fuel consumption and $\mathrm{CO}_{2}$ emissions are about three times more important in the take-off and landing phases. Based on Fig. 2(d), the CO emission is ca. $0.0085 \mathrm{~kg} . \mathrm{s}^{-1}$ for the take-off and landing phases, while it stabilizes at ca. $0.0022 \mathrm{~kg} \cdot \mathrm{s}^{-1}$ at cruise. Here again, $\mathrm{CO}$ emission during take-off and landing is nearly four times more than the cruise level. The same observation is made from Fig. 2(e), where $\mathrm{NO}_{\mathrm{x}}$ emissions are ca. $0.5 \mathrm{~kg} . \mathrm{s}^{-1}$ during take-off and landing phases, while it stabilizes at ca. $0.04 \mathrm{~kg} \cdot \mathrm{s}^{-1}$ at cruise. Thus, $\mathrm{NO}_{\mathrm{x}}$ emissions during take-off and landing are about 12 times increased compared to the cruise level.

Within the sub-tab "Fleet", the results of all the simulations at the same time are depicted if the post-processing option was ticked. Then, the consumption and emissions statistics of the entire fleet simulated are also depicted. For the purpose of demonstration, a fleet of five flights was created, depicted in Table 1 (refer to Fig. 1 to see the ACEMIS graphic interface while fleet simulation is running).

The fuel consumption and $\mathrm{CO}_{2}$ emissions distribution of the above fleet are shown in Fig. 3: there is a high fuel consumption and $\mathrm{CO}_{2}$ emission region near departure and arrival airports (green region, Fig. 3(a) and (b)), corresponding to the take-off and landing phases. 


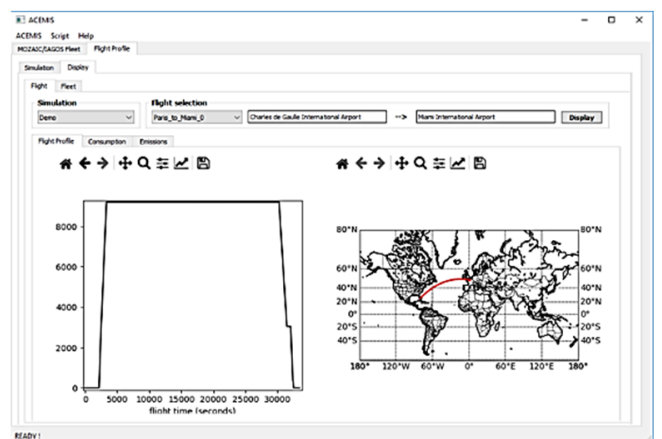

(a)

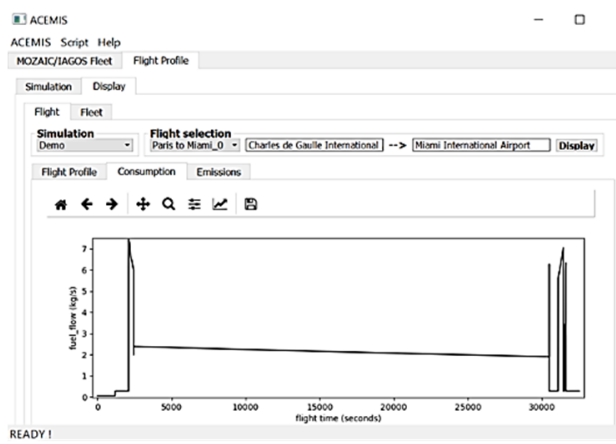

(b)

Dacemis

ACEMIS Sceipt Help

MOZACIIAGOS Feet Figh Protile

Smudation Disploy

Filpte Fleet

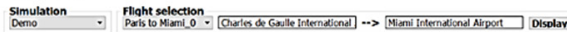

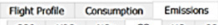

CO2 H2O NOX CO HC SO2

$H \leftarrow+a \div \alpha$ 回

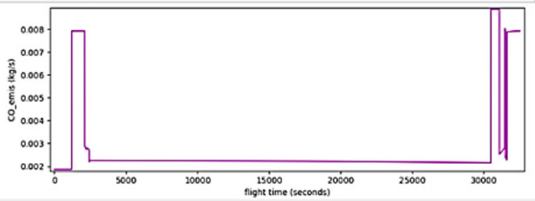

(d)
DI ACEMIS

ACEMIS Saipt Help

MOZACCIAGOS Fleet Filight Protil

Sindetion Displor

Flight Fleet

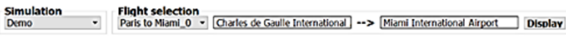

Ficht Protite Consumpotion Emissions

$H \leftarrow+Q \equiv \underline{W}$

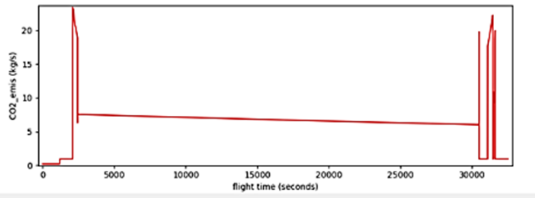

(c)

D ACEMIS

ACEMIS Scipt Help

MOZACIIAGOS Heet Filight Frotic

Sirulation Desclay

Five

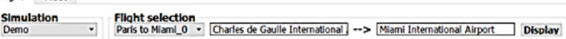

Filghe protite consumption Emisslors

CO2 120 NOX $C O$ HC 502

* $\rightarrow+a \equiv \leftarrow$ 目

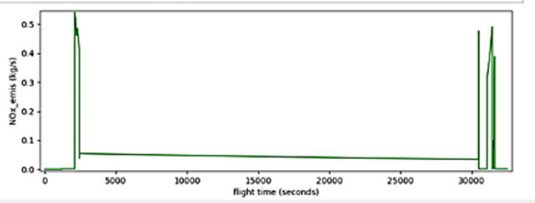

(e)

Figure 2: Display menu of "Flight Profile" part. (a) Flight altitude (left part) and orthodromic projection of the flight route on the map (right part); (b) Fuel consumption; (c) $\mathrm{CO}_{2}$ emissions; (d) $\mathrm{CO}$ emissions; and (e) $\mathrm{NO}_{\mathrm{x}}$ emissions, as a function of flight time.

The potential of the ACEMIS tool is depicted Fig. 4 hereafter: it shows the geographical distribution and intensity of $\mathrm{CO}_{2}$ emissions over a sample of approximately 10,000 flights from Frankfurt International Airport in Germany (based on the MOZAIC/IAGOS database). 


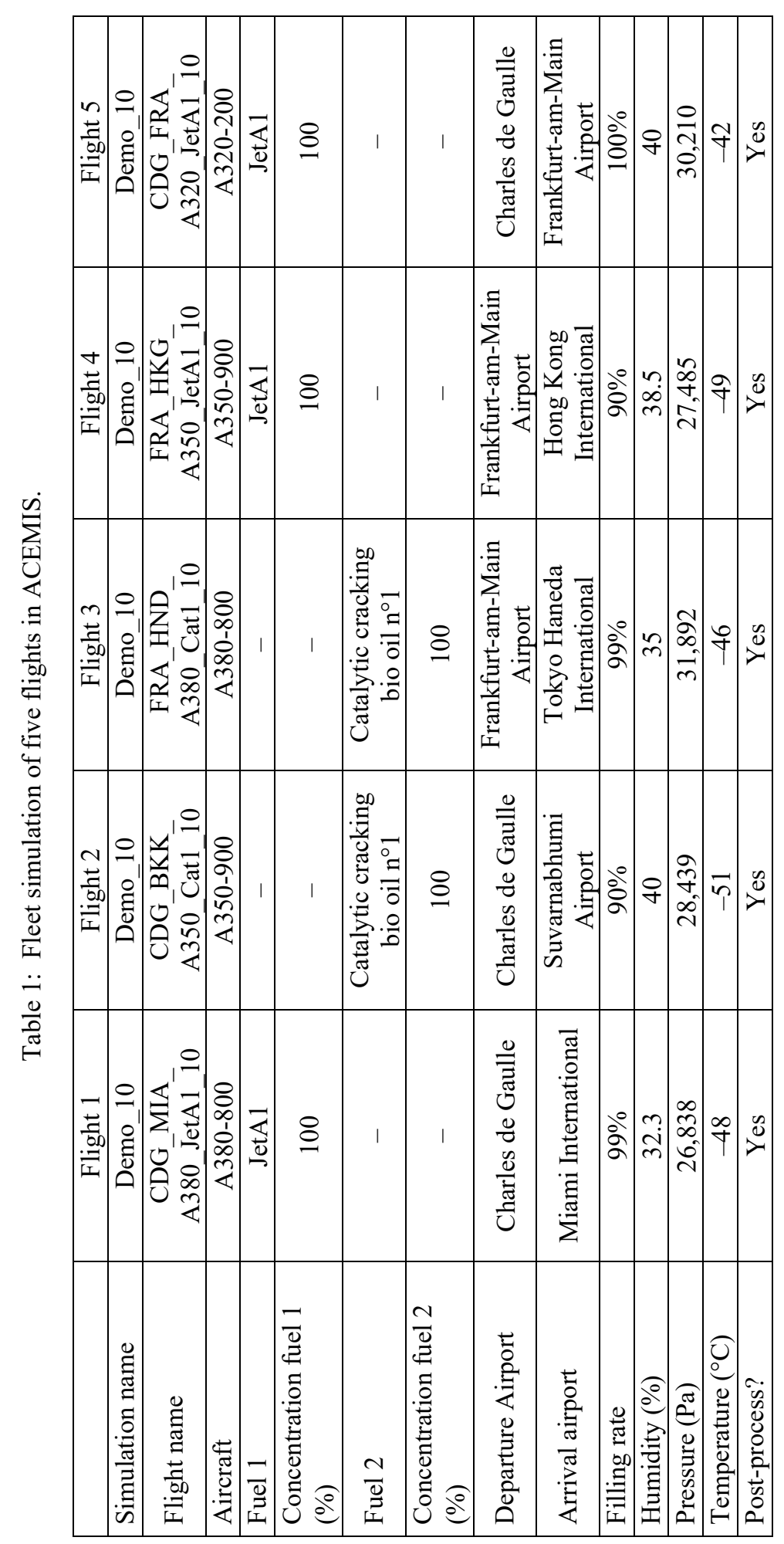




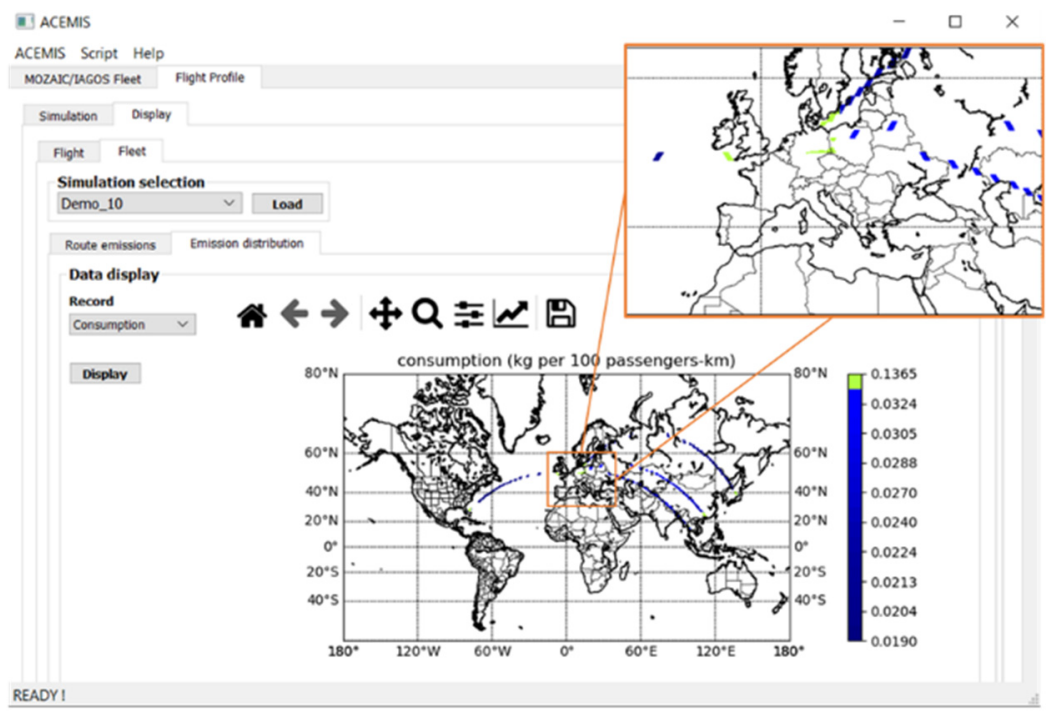

(a)

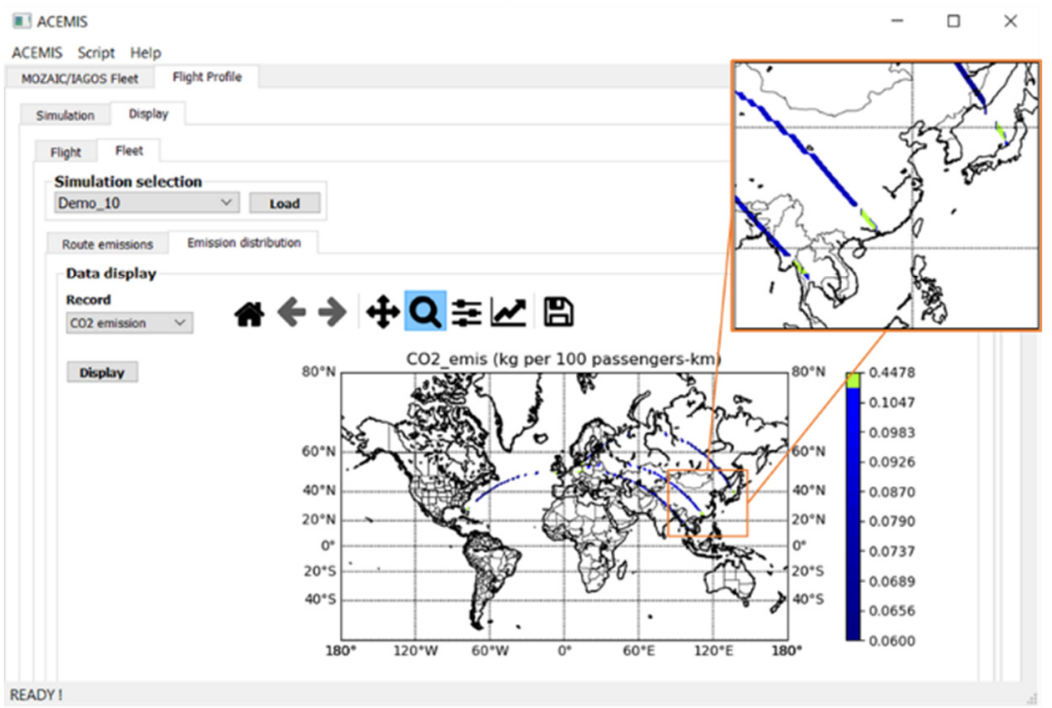

(b)

Figure 3: Display menu of "Flight Profile" part - Geographical distribution of (a) fuel consumption; (b) $\mathrm{CO}_{2}$ emissions along the fleet routes. 


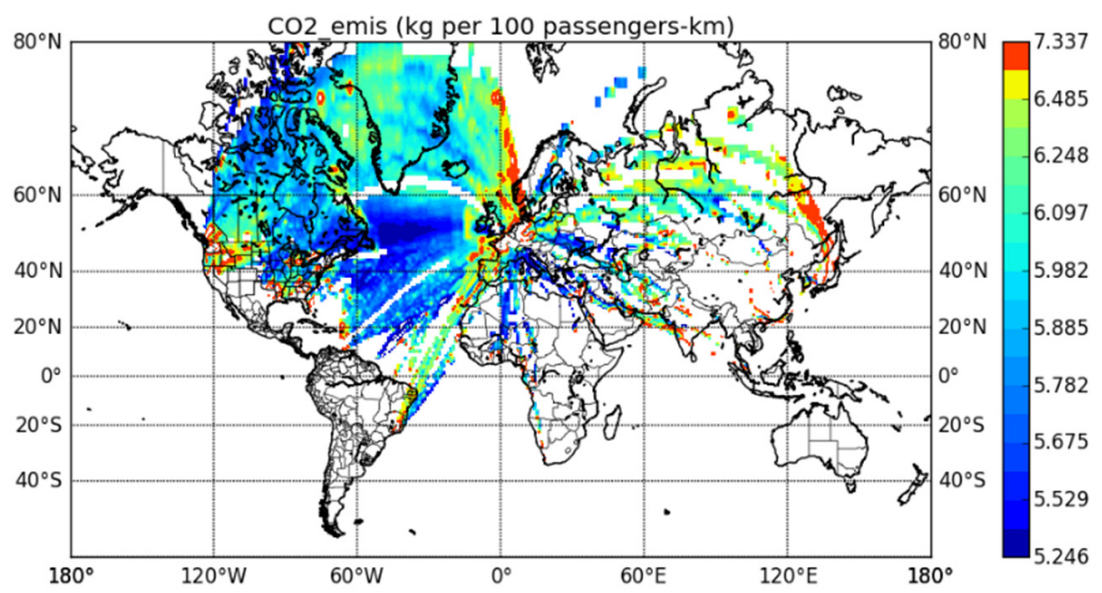

Figure 4: Display menu - Geographical distribution of $\mathrm{CO}_{2}$ emission over a sample of approximately 10,000 flights.

\section{DISCUSSION}

In order to validate the ACEMIS emissions model, a comparison with free and available calculators were done. ICAO has provided an online carbon emission calculator tool for $\mathrm{CO}_{2}$ emissions of a flight [11]. Furthermore, the CORSIA program has developed a tool called $\mathrm{CO}_{2}$ Estimation and Reporting Tool (CERT) [12], with more options about aircrafts, fuels and other parameters compared to the ICAO online simulator. Similarly, in France, the Direction Générale de l'Aviation Civile (DGAC) put in place an online carbon emission calculator known as TARMAAC (which stands for Traitements et Analyses des Rejets éMis dans l'Atmosphère par l'Aviation Civile) [13].

Hereafter, Table 2 represents the comparison between ICAO online calculator, CERT tool from CORSIA program, and ACEMIS for the fuel consumption and $\mathrm{CO}_{2}$ emissions related to the same flight profiles. The results show the same degree of magnitude for the total fuel consumption and the $\mathrm{CO}_{2}$ emissions. The ICAO calculator does not take all the parameters for the flight simulation, such as the aircraft used, the type of fuel, the weather data or the passenger-filling rate of the aircraft [11], whereas the CERT from CORSIA and ACEMIS do. In addition, ICAO calculator assumes that all aircrafts are entirely configured with economic seats. The values calculated are an average of the type of aircrafts, fuel used, and passenger fill rate information, available in the ICAO database [11]. Since JetA1 fuel is the most common fuel used today, it is assumed that the ICAO simulations are based on flights operating with $100 \%$ JetA1, so the same conditions were chosen with the CERT and ACEMIS. Therefore, ICAO results are approximated via several factors. On the other hand, the CERT seems to approximate the fuel used during the flights, as well as the $\mathrm{CO}_{2}$ emissions calculation (Table 2). ACEMIS results may be closer to reality, thanks to the calculations done in each flight segment, and experienced with the MOZAIC/IAGOS database [9]. Each ACEMIS simulation is specific to a single aircraft and engine, depending on various parameters. The results therefore are varying realistically, depending on the type of aircraft and its characteristics. 


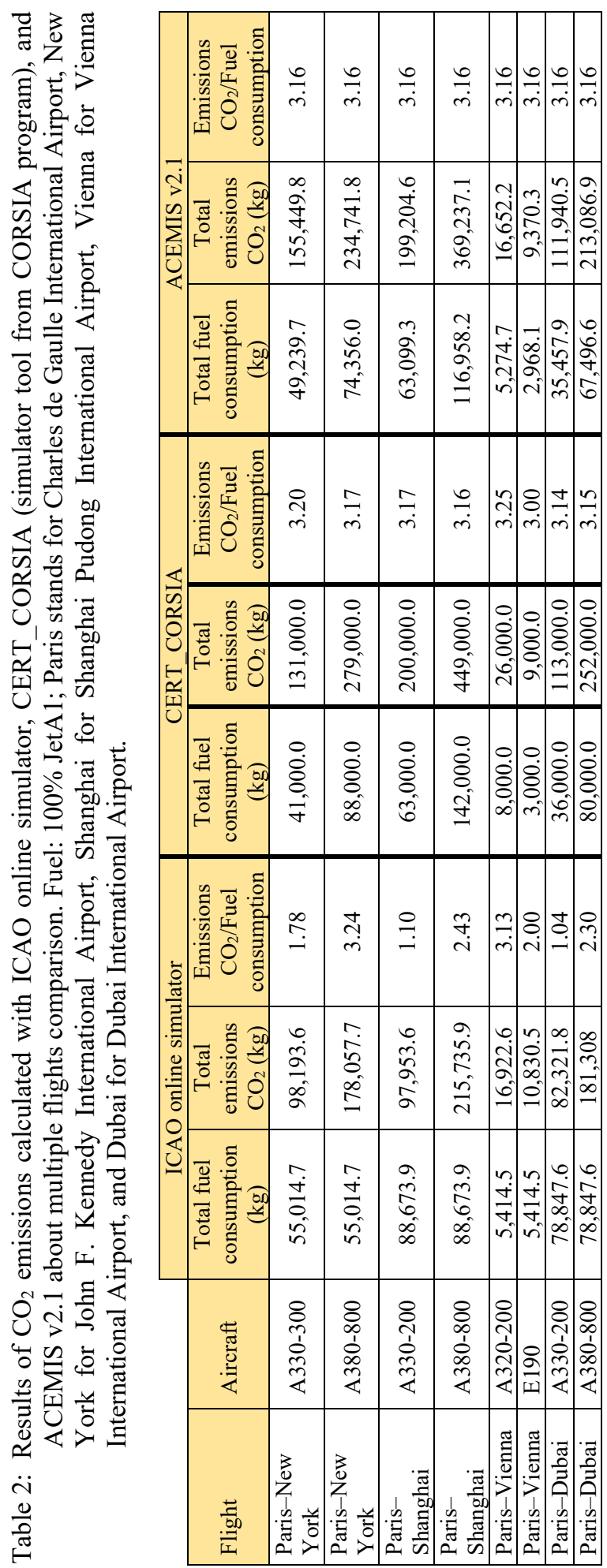




\section{CONCLUSION}

There is today a global consensus that climate change can be largely imputed to human activities, and that our society should move towards sustainable and renewable energy sources. ACEMIS tool is contributing towards aircraft traffic related pollution reduction. ACEMIS can be useful to airlines in many ways:

- for diagnosis purpose and continuous improvement of their environmental footprint, not only based on $\mathrm{CO}_{2}$ emissions, but also considering other pollutants to estimate the global impact of their fleet activity;

- to enable airlines to not only comply with the environmental requirements (such as the CORSIA program), but also to prevent further environment restriction based on the other chemical pollutants.

This is equally helpful to the regulatory bodies in the aviation sector (e.g. DGAC/DSNA in France), engineers, and environmental auditors (among others) to analyze the emissions levels. It also leads to the awareness of interested party about the most/the least polluted regions, along the flight path. This in turn could help to schedule future routes as avoiding climate sensitive regions might be the most promising approach to reduce the climate impact of non- $\mathrm{CO}_{2}$ emissions [14].

ACEMIS is a scalable tool developed using Python programming language. Due to the independent nature of the modules, the future aircraft technologies affecting the simulation can be easily integrated within existing or novel modules. With a simple update of the database files, it is possible to integrate new aeronautics developments, such as disruptive aircraft design, novel engines, biofuels, electricity and hydrogen technologies... The Capgemini Engineering group is currently working on new features such as simulation of noise around airports, inclusion of emission simulation of cargo flights, 3D results display and inclusion of electrical and hydrogen powered engines, in order to provide one of the first pollutants simulation of these novel technologies. The final objective is to get a solution that is beneficial to future users, thanks to quick updates and easy integration of new technologies.

Name: ACEMIS.

\section{SOFTWARE AVAILABILITY}

Developer: Capgemini Engineering.

Contact: Capgemini Engineering (www.altran.com).

Programming framework: Python.

Language: English.

Year first available: 2021.

\section{ACKNOWLEDGEMENT}

ACEMIS is the result of the collective discussions of numerous people of the Technology and Engineering Center of the Capgemini Engineering Group who worked in this project, at various time and interval. We would like to thank everyone who contributed, and particularly Sébastien Garnier and Thomas Noiret who initiated this work.

MOZAIC/CARIBIC/IAGOS data were created with support from the European Commission, national agencies in Germany (BMBF), France (MESR), and the UK (NERC), and the IAGOS member institutions (http://www.iagos.org/partners). The participating airlines (Lufthansa, Air France, Austrian, China Airlines, Iberia, Cathay Pacific, Air Namibia, Sabena) supported IAGOS by carrying the measurement equipment 
free of charge since 1994. The data are available at http://www.iagos.fr thanks to additional support from AERIS.

\section{REFERENCES}

[1] European Aviation Environmental Report 2019. https://www.easa.europa.eu/eaer/ system/files/usr_uploaded/219473_EASA_EAER_2019_WEB_HI-RES_190311.pdf.

[2] Aviation and the Global Atmosphere, IPCC special report, 1999. https://www.ipcc.ch/site/assets/uploads/2018/03/av-en-1.pdf.

[3] The Growth in Greenhouse Gas Emissions from Commercial Aviation, Part 1 of a series on airlines and climate changes, 2019. https://www.eesi.org/papers/view/factsheet-the-growth-in-greenhouse-gas-emissions-from-commercial-aviation. Accessed on: 19 Apr. 2021.

[4] Aviation: 2 to 3 times more damaging to the climate than industry claims, 2018. https://www.transportenvironment.org/news/aviation-2-3-times-more-damagingclimate-industry-claims. Accessed on: 19 Apr. 2021.

[5] Reducing emissions from aviation. https://ec.europa.eu/clima/policies/transport/ aviation_en\#tab-0-0. Accessed on: 19 Apr. 2021.

[6] International Civil Aviation Organization (ICAO), Annex 16 to the Convention on International Civil Aviation, Environmental Protection, vol. IV, Carbon Offsetting and Reduction Scheme for International Aviation (CORSIA), 1st ed., Oct. 2018 (full report).

[7] Schaefer, M., Methodologies for aviation emission calculation: A comparison of alternative approaches towards 4D global inventories. Thesis, Berlin University of Technology, 2006. DOI: 10.14279/depositonce-1476.

[8] Air Transport Action Group, Facts and Figures. https://www.atag.org/factsfigures.html. Accessed on: 19 Apr. 2021.

[9] In-service Aircraft for a Global Observing System. https://www.iagos.org/, and data http://www.iagos-data.fr/. Accessed on: 19 Apr. 2021.

[10] DuBois, D. \& Paynter, G.C., Fuel flow Method2 for estimating aircraft emissions. SAE Transactions, 115(1), pp. 1-14. https://www.jstor.org/stable/44657657.

[11] International Civil Aviation Organization (ICAO), ICAO Carbon Emissions Calculator. https://www.icao.int/environmental-protection/CarbonOffset/Pages/ default.aspx. Accessed on: 19 Apr. 2021.

[12] International Civil Aviation Organization (ICAO), Carbon Offsetting and Reduction Scheme for International Aviation (CORSIA), $\mathrm{CO}_{2}$ Estimation and Reporting Tool (CERT). https://www.icao.int/environmental-protection/CORSIA/Pages/CERT.aspx. Accessed on: 19 Apr. 2021.

[13] Calculateur d'émissions de gaz à effet de serre de l'aviation, Direction Générale de l'Aviation Civile. https://eco-calculateur.dta.aviation-civile.gouv.fr/. Accessed on: 19 Apr. 2021. (In French.)

[14] Climate Change 2013, The Physical Science Basis, Intergovernmental Panel on Climate Change, Report, 2013. https://www.ipcc.ch/site/assets/uploads/2018/02/W G1AR5_all_final.pdf. 